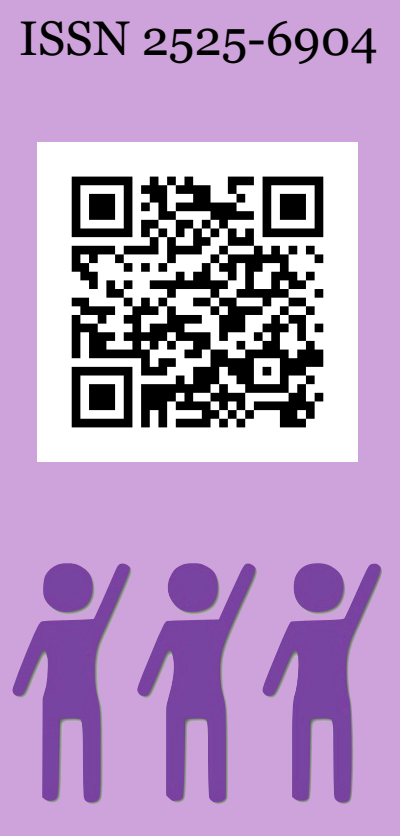

\title{
Trajetória política de Marília Arraes na esquerda em Pernambuco
}

\author{
Algumas questões de gênero
}

Lady Selma Ferreira AlBERnAZ, Universidade Federal de Pernambuco Leonardo Leal EsTEVES, Universidade Federal de Sergipe

Suênia Claudiana do N. PINTO, Universidade Federal de Pernambuco

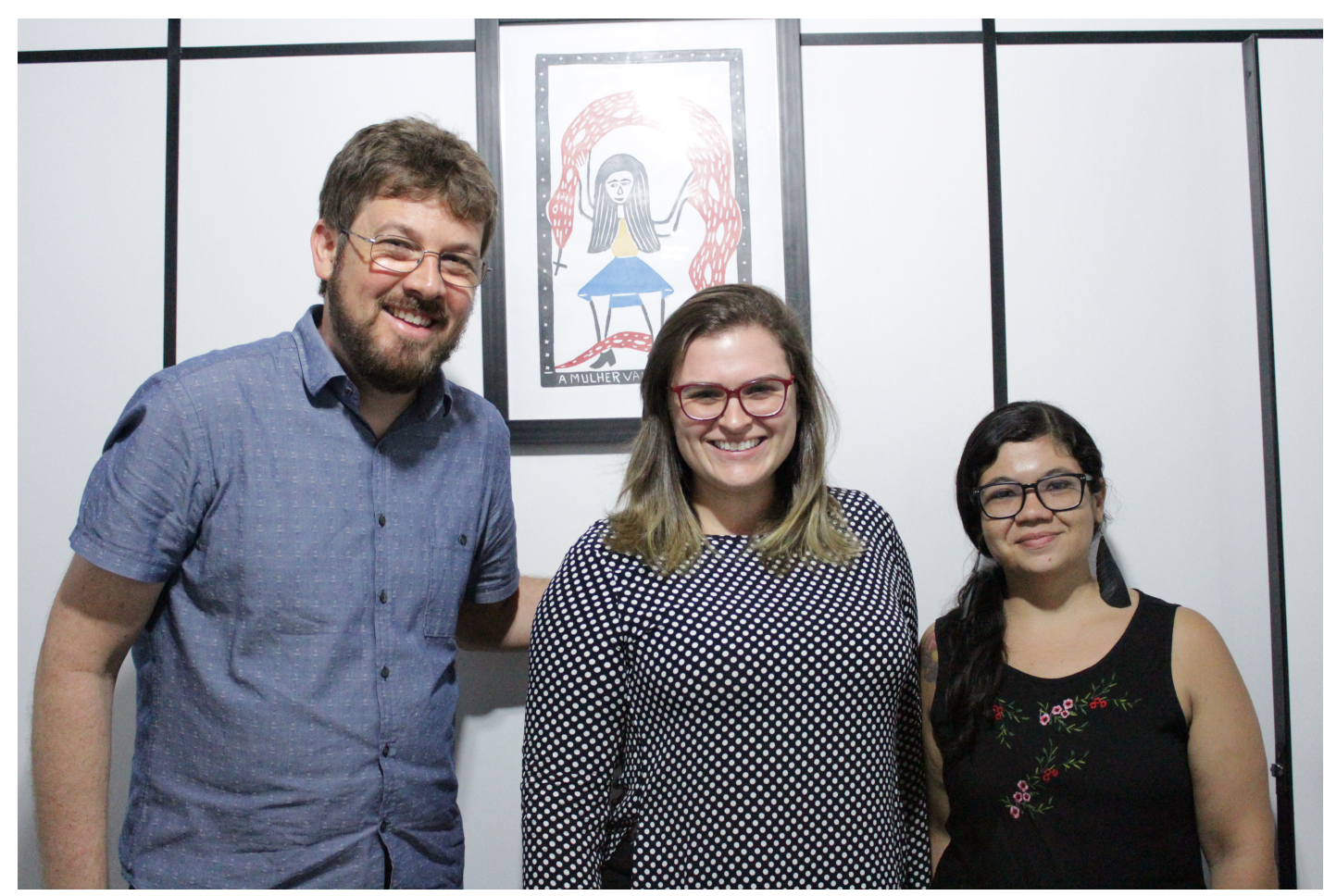

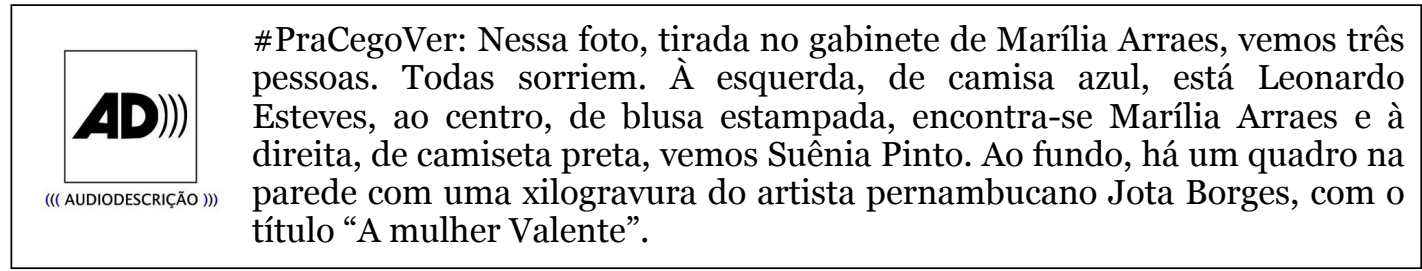

\section{\#mulherescompartido}


A teoria de gênero nos permite compreender e analisar a atuação das mulheres no campo da luta política. De acordo com teóricas feministas, tais como Joan Scott (1989), Henrieta Moore (1997) e Marilyn Strathern (2006), gênero constitui-se como princípio organizador da vida social, atribuindo papeis, espaços, lugares e posições para as pessoas, para os objetos e para a natureza. É por meio do gênero que nossos sentimentos de ser homem e ser mulher ganham valor moral que orientam nossa ação com as outras pessoas, com os objetos, com o espaço e com o ambiente. Por isso as ideias do que vem a ser homens e mulheres reais variam, consoante sistemas de valores de gênero em contextos específicos, devendo ser culturalmente situadas.

Para Strathern, (2006, p.11) gênero diz respeito "aquelas categorizações de pessoas, artefatos, eventos, sequências etc. que se fundamentam em imagens sexuais - nas maneiras pelas quais a nitidez das características masculinas e femininas torna concretas as ideias: das pessoas sobre a natureza das relações sociais". Para Scott (1989, p. 23) "o gênero é um meio de decodificar sentido e compreender relações entre diversas formas de interação humana, legitimando e construindo as relações sociais". Portanto, gênero constitui-se num sistema de significados utilizado para designar a organização social, incluindo as relações entre sexos, apontando para o caráter social das desigualdades entre homens e mulheres. Dessa forma, o gênero configura-se num elemento importante para compreender as assimetrias e desigualdades que perpassam a esfera política. Considerando que no âmbito de uma sociedade patriarcal e de uma cultura androcêntrica, os homens possuem historicamente maior presença e visibilidade no campo da atuação pública em relação às mulheres, é pertinente reconhecer que a autonomia, protagonismo e atuação política delas, encontra-se enredada em múltiplas relações de poder específicas, em decorrência do seu sexo, que implicam em conflitos, tensões, disputas simbólicas e resistências particulares.

A trajetória política de Marília Arrares é um exemplo dos processos de enfrentamentos de gênero no campo da política. Nasceu em 1984, poucos anos após seu avô - um dos maiores líderes políticos da esquerda brasileira, Miguel Arraes- voltar do exílio. Viveu e se formou em um ambiente fortemente influenciado pelas questões da política partidária. Foi eleita como Vereadora no Recife por mais de um mandato, quando decidiu entrar definitivamente na vida política em 2008. Nas últimas eleições de 2018, disputou a indicação para a pré- 
candidatura ao governo do estado de Pernambuco e vinha liderando todas as pesquisas de intenção de voto, até que a cúpula do Partido dos Trabalhadores (PT) decidiu não levar adiante a sua indicação, para apoiar à reeleição do então governador Paulo Câmara. Marília resolveu então se candidatar ao cargo de deputada federal e foi eleita com o segundo maior número de votos ao cargo no estado. Segundo Marília, no ambiente extremamente machista da política, "a mulher não ocupa os espaços se não botar o pé na porta. Se for entrar pedindo licença, não entra em canto nenhum".

Para compreender um pouco mais os enfretamentos e a trajetória de Marília Arraes no campo da política, a entrevistamos na tarde do dia 04 de dezembro de 2018, em seu gabinete, localizado no terceiro andar da Câmara Municipal do Recife. Após uma reunião de uma das comissões das quais é relatora, ela nos recebeu em uma sala em que havia, de um lado, um quadro com a imagem do seu avô, Miguel Arraes, junto a uma poesia de Bertolt Brecht e, de outro, uma xilogravura do artista pernambucano Jota Borges, com o título "A Mulher Valente". Ali ela nos contou um pouco de sua história, sua atuação, suas inquietações e seus sonhos.

Comentário: Primeiramente, gostaríamos de agradecer pela gentileza e pela disponibilidade em conceder esta entrevista. Sabemos que a sua vida é muito corrida e que seria difícil disponibilizar tempo, sobretudo neste período...

Marília Arraes: Por nada, oxente! Isso é bom pra a gente também... Ter esta oportunidade de mostrar um pouco o que pensa. Principalmente, na forma como seu deu a candidatura e tudo mais...

Pergunta: Para iniciar, gostaríamos que você nos contasse um pouco como foi sua infância. Onde nasceu? Onde morava? Um acontecimento histórico ou pessoal que lhe marcou? Para entender um pouco esta sua trajetória política.

Marília Arraes: Eu nasci e me criei no Recife. Agora a época em que eu nasci, especificamente, é que se deu esta peculiaridade da 
formação política que eu tive. Nasci em um ambiente que se vivia política, pelo fato de meu avô [Miguel Arraes] ter recentemente voltado do exílio. Nasci em 1984. Toda minha família estava muito envolvida com a questão das eleições diretas. Não somente meu avô, mas até outros familiares que não são agentes políticos hoje em dia... Se falava muito sobre isso, se vivia muito o assunto... E foi neste ambiente em que eu nasci. Logo depois, meu avô se elegeu como governador pela segunda vez, aqui de Pernambuco. Quando ele assumiu, eu ia fazer três anos. Enfim... Sempre vivi neste ambiente e sempre com formação de esquerda. Mais ou menos com quatorze anos, foi que eu comecei a participar mais das atividades políticas. Participei de movimentos de juventude e, depois, na faculdade... Sou advogada, estudei na Federal [Universidade Federal de Pernambuco], em Direito... Participei do movimento estudantil... Então, fazia em paralelo à política estudantil, a política macro... E, logo depois que me formei, me candidatei a primeira vez a Vereadora... Está fazendo dez anos, neste ano... E, ganhei a primeira eleição. Daí foram três mandatos... E, sempre... O papel do Vereador é muito peculiar, porque a competência no que se pode legislar é muito restrita. A competência legislativa é muito restrita... Então, sempre, o nosso papel foi mais de fiscalização. Ainda quando eu era base de governo, a gente exercia muito esta questão de fiscalizar, de cobrar. Fui Presidente da Comissão de Justiça aqui da casa, que é por onde passam todos os projetos. Eu considero como sendo um dos cargos políticos mais importantes da cidade. Porque é praticamente quem decide, junto com o Presidente [da Câmara dos Vereadores], quais os projetos que vão à pauta... Fui Presidente desta Comissão durante dois anos do meu primeiro mandato. E, ainda assim, cobrava! Não tinha um papel subserviente. Depois fui chamada para ser Secretária... Fui Secretária durante um ano na Prefeitura do Recife. Não foi uma boa experiência. Na verdade, minha ida para a oposição iniciou durante este ano que passei como Secretária, que vi quais eram as prioridades e quais não eram as prioridades do governo. Saí, fui para a oposição. Fui para a vice-liderança [da oposição]. Depois me reelegi e assumi a liderança da oposição. No terceiro mandato, saí da liderança para me dedicar à précampanha ao Governo do estado. A gente estava construindo esta candidatura... Saí no início deste ano... Não foi possível haver a candidatura ao Governo. Me candidatei à Deputada Federal. Me elegi. Estamos aqui! 
Pergunta: Como foi a sua formação junto à família, enquanto criança, em termos de valores, política, etc.?

Marília Arraes: É como eu falei... Minha formação sempre foi de esquerda. E a formação política sempre esteve muito presente em minha vida... Eu acho que até muito mais do que outros primos ou irmãos que são mais novos, por conta do momento que a gente estava vivendo... Minha mãe, por exemplo, me colocava pra dormir e contava histórias da Revolução Cubana, da Revolução Chinesa e tal... Isso não foi feito com outros da família que viveram e nasceram em outra época. Então, minha formação sempre foi de esquerda e pela criação desta consciência cidadã deste nosso campo político.

Pergunta: E do ponto de vista da Religião? Vocês seguiam alguma religião, tinham algum envolvimento?

Marília Arraes: Católica.

Pergunta: Houve algumas pessoas que lhe marcaram? Pessoas influenciaram você positiva ou negativamente?

Marília Arraes: Claro que a figura de Arraes [Miguel Arraes] é Hors Concours... Não concorre com outros. Mas, mais para minha vida adulta, eu tive uma relação muito próxima a Fernando Lyra1. Que foi, sem dúvida, uma das pessoas que mais marcou a minha vida política, dos vinte anos pra cá. Dos meus vinte, vinte e um anos, até ele falecer, a gente teve uma relação bem próxima em termos de orientação... Exministro Fernando Lyra.

1 Fernando Soares Lyra foi deputado estadual pelo MDB entre 1967 e 1971, assumiu a liderança do partido por diversas vezes entre os anos 80 e 90 e a liderança do PSB nos anos 90. Ao longo de sua trajetória, teve importante atuação em comissões e, entre 1987 e 1991, integrou a Constituinte. Por sua atuação no Congresso, recebeu a medalha de Mérito Legislativo na Câmara dos Deputados em 1985. Foi deputado pelo MDB (1971-1979), PMDB (1979-1991), PDT (1992-1995) e PSB (1995-1999). Teve uma forte aproximação e passou a ser um dos coordenadores da campanha de Tancredo Neves à Presidência da República. Em 1985, foi nomeado a Ministro da Justiça, quando o vice-presidente José Sarney assumiu à Presidência (Carta Capital, 2013). 
Pergunta: E em termos de influências negativas?

Marília Arraes: Eu acho que todo o contato que a gente tem na política, a gente tem que usar para enriquecer nosso conhecimento, para amadurecer... Mesmo que as experiências não sejam positivas. Considero que toda a relação que eu construí ou desconstruí foi positiva para a minha formação política.

Pergunta: Agora falando aqui um pouco de Pernambuco... Como descreve, do ponto de vista político e social, o estado e sua relação com o restante do país?

Marília Arraes: Pernambuco vive numa situação peculiar que é a falta de uma liderança política. O brasileiro é muito personalista. Claro, que tem a força dos partidos... Mas, em termos de ter uma liderança política, Pernambuco hoje tem esta carência de ter uma pessoa, um líder... Seja de qual campo for, da esquerda, da direita... A gente acabou de viver uma eleição em que o povo escolheu por eliminação o candidato a Governador ${ }^{2}$. Ninguém foi para a urna com aquela empolgação, com aquela vontade de eleger com o coração... Não foi! Porque a gente continua neste processo de carência de uma liderança e de falta de posicionamento político. Acho que o futuro de Pernambuco em relação à própria gestão é muito incerto. Pernambuco é um estado que deve, que deve bastante, que está com a saúde financeira bastante prejudicada, que tem uma tendência natural - por ser do Nordeste - de sofrer mais dificuldades... Não somente por uma eventual perseguição, mas porque a gente não vê perspectiva, neste governo, que haja diminuição da desigualdade regional, como houve nos governos do PT. Então, isto já é um dificultador para Pernambuco. A falta de competência de foco, de determinação do governador é outro dificultador... E a falta de posicionamento político. Porque o que a gente acha... Espero que a gente esteja errado... Mas, o que a gente acha é que a tendência do Governo Bolsonaro é, além de menosprezar o Nordeste, perseguir os adversários políticos. Qual vai ser o posicionamento dele [referindo-se ao

2 O Governador Paulo Câmara foi reeleito ao Governo do estado de Pernambuco, no primeiro turno das eleições de 2018, com 50,7\% dos votos válidos. 
Governador Paulo Câmara]? Porque nós sabemos que o Governador agora somente colou a imagem dele com o Presidente Lula para neutralizar uma rejeição enorme que tinha, de mais de $70 \% \ldots$ Historicamente foi o Governador mais rejeitado da história de Pernambuco. Então, o que ele vai fazer para amenizar essa situação? Vai aderir ao Governo Bolsonaro? Vai continuar na oposição? Ele tem essa determinação política, como teve Arraes no seu último Governo?... No terceiro Governo, que se colocou na oposição, como adversário de Fernando Henrique... E Fernando Henrique puniu Pernambuco... Então a gente está sem saber o que vai acontecer com o estado, por conta de quem hoje lidera politicamente Pernambuco.... Então, eu acho que é esperar este primeiro ano de Governo para ver...

Pergunta: Você já falou um pouco de como se envolveu com a política. Mas como efetivamente você tomou a decisão de entrar na vida política, de se candidatar a Vereadora e aos outros cargos?

Marília Arraes: Antes de me candidatar a Vereadora, já vinha cogitando a ser candidata em outra eleição... Na eleição anterior. Não foi possível, pela conjuntura do momento. E, comecei a trabalhar esta possibilidade de me candidatar a Vereadora. Não era a única opção da minha vida! Eu estava concluindo o curso de Direito. Eu estava também estudando na época pra concurso... Pensava em fazer o concurso para o Instituto Rio Branco... E, na verdade, a gente começou a construção... Fernando Lyra foi um dos que mais me incentivou e me ajudou... Me orientou, enfim... E, cresceu esta ideia. A gente se candidatou, deu certo e estamos até hoje.

Pergunta: Você também fazia parte de um grupo jovem, não é?

Marília Arraes: É, eu era da juventude do partido nacional [PSB] e tinha essa militância nas duas esferas...

Pergunta: Participou de Diretórios Acadêmicos? 
Marília Arraes: Sim, participei de movimentos estudantis na Federal [Universidade Federal de Pernambuco]... Até foi extinto o grupo do qual eu fazia parte... Mas tinha muita gente boa que era militante com a gente. E, montamos a eleição, deu certo, continuamos!

Pergunta: Por quais partidos já passou?

Marília Arraes: PSB e PT.

Pergunta: Quais foram os motivos da mudança? Sabemos que houve um certo mal estar, em relação ao Governo...

Marília Arraes: Quando o PSB deu uma guinada à direita, fez uma aliança com todos os partidos da direita para se manter no poder, para fazer oposição à Presidenta Dilma, eu rompi politicamente com o PSB. Apesar de continuar nele por mais um ano e um pouquinho e depois, fui para o PT.

Pergunta: Quais as pautas que você defende na política?... Pautas que são importantes neste momento...

Marília Arraes: Infelizmente, no momento atual, temos que lutar pela manutenção dos direitos, quando a gente poderia estar brigando pelo avanço de algumas conquistas. A gente está brigando para mantê-las. Então, hoje, a pauta dos direitos do trabalhador é algo essencial que a gente tem que levar em conta... Porque a gente sabe que o grande objetivo deste golpe que foi dado foi retirar os direitos do trabalhador, foi entregar o nosso patrimônio nacional... Então, a pauta contra as privatizações, contra a retirada de direitos, tanto dos trabalhadores, quanto das mulheres, a mulher trabalhadora ou não... Tudo isso, a gente precisa se unificar, pra unificar o nosso campo político à esquerda... Passar por cima das diferenças porque, se a gente permitir que avancem neste sentido, pra a gente voltar a reconquistar... O que a gente perder em quatro anos, a gente vai demorar cinquenta anos para reconquistar. Então, eu acho que esta é a grande responsabilidade do 
nosso campo político hoje... Porque, na verdade, o que esse governo fez, foi usar uma cortina de fumaça na eleição, que foi a pauta da moralidade, da família, da moral... E que, na verdade, encobria o entreguismo, encobria os interesses patronais de aumentar o lucro, de diminuir os encargos, enfim... E fazer o trabalhador pagar o pato.

Pergunta: Qual o papel da oposição no atual cenário político?

Marília Arraes: É a gente... Não tem como a gente ter essa atuação, sem a legitimidade das ruas. Se a gente não tiver a capacidade de mobilizar as pessoas, de conscientizar as pessoas do que está acontecendo, dos riscos que a gente está correndo e que as pessoas respaldem a nossa atuação lá no congresso...Realmente, vai ficar bem difícil. Esse desafio vai ser muito maior... Porque nós, durante os treze anos de governo... Nós conseguimos que tivesse uma classe que era pobre... Passou... Eu não chamo de classe média... Mas passou a ter acesso a bens de consumo... Passou a ter acesso a espaços que não tinham antes... E que a gente, durante este processo de ascensão social, não conseguiu fazer com que as pessoas entendessem a razão daquilo estar acontecendo. Então, nós sofremos com a teoria da ilha... De que cada um seria uma ilha e que tinham conquistado aquilo, apenas pelo próprio trabalho. É claro que o trabalho foi importante! Não podemos menosprezar o esforço que as pessoas depreenderam. Mas, foi fruto também de uma política diferente. Por que as pessoas sempre trabalharam muito e nunca tinha acontecido isto?... Então, nós não tivemos essa capacidade... Durante esse processo, de criar uma classe que, além de consumidora, além de ascenderem socialmente, tivessem essa consciência cidadã.... Então, agora vai ser difícil. Mas a gente vai ter que fazer... Correr atrás deste tempo perdido e fazer o possível, porque, sem a gente ter uma população mobilizada, consciente... Uma classe trabalhadora consciente de que é uma classe trabalhadora... E dos riscos que que está correndo durante este processo e que vai impactar na próxima geração... Realmente, a nossa atuação, vai ser dar murro em ponta de faca... A gente precisa estar lá no congresso, atuando e combatendo, mas com a população fazendo pressão. Porque aconteceu com a reforma da previdência... Tiveram medo de votar antes da eleição. Por que? Porque a gente conseguiu mobilizar as pessoas. Então a gente vai ter que pegar essas pautas e mostrar o quanto são importantes... E 
combater o discurso fácil que eles têm de que aumentaria o emprego se diminuíssem os encargos... A gente tem que sair provando que isso não é verdade. Isso já está acontecendo! Já está se mostrando que não é! Então, esse é o nosso grande desafio... Nosso desafio lá no congresso é um. Mas o desafio maior é junto às pessoas. É a gente manter essa proximidade e essa mobilização popular. $\mathrm{E}$ isso vai ser muito mais difícil no contexto atual, de corte de imposto sindical... Até porque a gente sabe que, quem representa os grandes grupos econômicos tem acesso a recursos e direcionam os recursos para onde querem... É só olhar o caixa dois de Bolsonaro... Agora a classe trabalhadora precisa de uma forma de se movimentar... Então, a gente vai precisar da unidade mesmo da classe trabalhadora, do nosso campo político... Passar por cima de divergências, conseguir articular, conseguir se unir com os outros companheiros e colocar essa pauta em primeiro lugar.

Pergunta: O que significa estar na vida política partidária? Sabemos que existem muitos desafios também por estar fazendo parte de um partido... Haja vista o que aconteceu com a sua candidatura ao Governo. Às vezes você tem que recuar, enfim... Como é que é fazer parte de um partido?

Marília Arraes: Eu acho que é importante sempre vir a figura do partido político, como essencial para a democracia... Eu acho que o que puder fazer para fortalecer... Não fortalecer o partido, mas fortalecer a consciência partidária... Acho que esta cultura brasileira personalista que a gente tem é fruto da dificuldade que a gente teve historicamente de consolidar a democracia. Se você observar em lugares em que a democracia é efetivamente consolidada, a visão das pessoas é outra em relação ao partido.... E o comportamento dos políticos em relação aos partidos também é outro. Então, eu acho que isto é um processo que a gente vai ter que passar... O que não pode é jogar a toalha... Desistir dele... Então eu acho que é lutar pra consolidar a importância dos partidos, a seriedade com que os políticos e com que a população encara o partido político na consolidação da democracia.

Pergunta: Qual a sua concepção sobre direita, esquerda e centro na política brasileira? De fato existe uma ideologia mais à esquerda ou à direita ou se esta discussão estaria desgastada no Brasil? 
Marília Arraes: Eu acho que essa pergunta faria sentido num contexto político de cinco anos atrás, vamos dizer. Quando eu disputei minha primeira eleição, parece que era moda dizer que que não existia mais esquerda e direita. Hoje está escancarado que existem dois lados. Existe um lado que, além de conservador do ponto de vista moral, é liberal do ponto de vista econômico e quem sofre com isso é o trabalhador. Isso daí acho já está bem claro quem é esquerda e quem é direita. Eu acho que agora a população consegue enxergar isso daí.

Pergunta: Acha que há machismo na política? Quais as estratégias utilizadas por você para lidar com situações de machismo na política e no cotidiano da vida pública e privada?

Marília Arraes: Tem machismo não só na política, mas a política reproduz o machismo da sociedade. Agora claro que é um ambiente predominantemente machista. $\mathrm{Eu}$ fui a quarta deputada federal que se elegeu na história de Pernambuco, somente quatro mulheres foram eleitas deputadas federais aqui no nosso estado, na história inteira de Pernambuco. Aqui na Câmara do Recife, na história toda da cidade, somente 13 mulheres foram vereadoras. Então, Pernambuco é um estado bem machista na política. E no cotidiano parece que a situação está piorando, com essa saída do armário de muita gente, de muito machista, de muito preconceituoso que teve a oportunidade de colocar para fora o que queria dizer há muito tempo. Mas a gente lida enfrentando, enfrentando... Eu acho que mulher não ocupa os espaços se não botar o pé na porta. Se for entrar pedindo licença, não entra em canto nenhum. Então é assim, que me comporto, na vida e na política. E acho que nesse processo aí de retirada da candidatura teve um machismo, teve machismo sempre, em todas as abordagens de construção e de desconstrução dessa candidatura teve um viés machista, de preconceito tanto por eu ser mulher, quanto por eu ser mais jovem. Mas eu acho que a gente já avançou bastante. Eu acho que o fato de a gente ter ousado se colocar como candidata, de ter crescido como cresceu já foi um avanço, espero que a gente consiga com isso abrir outras portas pra gente e para outras mulheres. 
Pergunta: É provável que o PT tenha deixado de avançar no primeiro turno em Pernambuco, por conta desta frustração que houve em barrarem a sua candidatura e fazerem este rearranjo, não é?

Marília Arraes: Pois é... Porque, na verdade, a gente está em um momento de resgatar a esperança das pessoas na política. A gente não pode mostrar que é mais um que senta, faz um acordo e que está tudo certo. Isto não aconteceu só em Pernambuco... Pernambuco foi o lugar que teve mais destaque, por conta de como a candidatura tinha praticamente se consolidado. Das chances que a gente tinha de se eleger. Então teve um destaque nacional grande... Mas aconteceram acordos assim em outros estados. Isso prejudicou. Isso prejudica o que a gente realmente quer. Agora eu acho que a mudança de visão, em relação a articulações deste tipo, depende muito de uma virada geracional... Porque a gente está falando de uma geração que hoje está à frente destas articulações, que viveu um outro momento político, diferente do que a nossa geração viveu, por exemplo... Então, eu acho que isso é uma questão de tempo, de rearrumação dos espaços, para a gente mudar esta forma de fazer política.

Pergunta: O Brasil vivenciou momentos tensos durante o último pleito presidencial. Conte-nos como experenciou este momento significativo para a História do País?

Marília Arraes: Muito difícil! Principalmente pela dificuldade de a gente dialogar com algumas pessoas que a gente via que seriam prejudicadas, que vão ser prejudicadas agora com a eleição do candidato que ganhou a eleição e que na verdade, não argumentavam, não agiam racionalmente. Apesar de que aqui no nosso estado de uma forma geral, não foi tão difícil quanto em outros. Mas, a gente vê com bastante preocupação. E como eu falei, se a gente tivesse sido 10\% bolivariana do que nos acusam, isso não estaria acontecendo.

Pergunta: Como encara o debate sobre gênero e sexualidade tão reivindicado e usado nos últimos anos no cenário político brasileiro? 
Marília Arraes: Veja, é como eu respondi uma pergunta anterior: utilizam esse debate como cortina de fumaça para incitar o ódio e a vontade de muita gente, que muita gente tinha de dizer isso e que estava calada. Então, esse debate termina predominando em todas as discussões, o debate do ódio, do preconceito, do machismo, da tradicional família brasileira, termina permeando as discussões e serve pra encobrir o real objetivo, que não é tão diferente - talvez seja até um pouco pior, mais aguçado - mas não é tão diferente de outros governos neoliberais. Talvez esse, por ter essa cortina de fumaça encobrindo essa real intenção, as intenções maléficas para o povo, para a soberania nacional sejam bem piores. Porque o que a gente vê é o movimento da elite, da elite que tentou ganhar a eleição quatro vezes e não conseguiu, deu o golpe e que, pode até tolerar uma democracia, se ela não vier com a ascensão da classe trabalhadora, com a soberania nacional. Então, o perigo além do retrocesso social que a gente pode ter, que isso é grave e pior, retrocesso social respaldado por uma maioria da população, esse é o perigo. Mas o perigo maior é porque encobre a consciência de muita gente que está apoiando isso e que vai se prejudicar... Mesmo que ache que esteja socialmente num papel opressor... Mas que vai se prejudicar por essas outras políticas.

Pergunta: Você acha que o discurso do presidente eleito autorizou ações violentas sobre o corpo da mulher, dos LGBTQI+, dos negros/as, nordestinos/as?

Marília Arraes: Autorizou com o discurso que ele incita. Ele teve atitudes autorizativas, mesmo que não tenha autorizado expressamente, isso aí sem dúvidas! Ações valem mais do que palavras.

Pergunta: Como observa a participação das mulheres brasileiras em cargos políticos ou de decisão?

Marília Arraes: A gente ainda tem muita dificuldade pelo papel social que a gente desempenha, pelo preconceito que a gente enfrenta quando entra na vida púbica, pela dificuldade em casa, pela dificuldade de entrar em determinadas articulações e determinadas conversas, de participar de cúpulas de partidos, digamos assim, isso 
acontece em todos os partidos. É uma dificuldade muito maior, são mais barreiras que a gente tem que ultrapassar. Então, eu acho que quando a gente tem um cargo político, representativo, a gente tem obrigação de com esse cargo inspirar mais mulheres, fomentar a autoconfiança de muita mulher que quer participar, não somente da política, mas de outros espaços... Assim, a gente tem que inspirar essa autoestima das mulheres para isso, essa autoconfiança para quebrarem mais barreiras e para estimular a sororidade de alguma maneira também, então eu acho que é muito desafio que a gente tem pela frente.

Pergunta: O que pensa sobre o Brasil de hoje? Como você vê o Brasil neste atual cenário?

Marília Arraes: Incerteza. A gente sabe as intenções desse atual governo. Aliás, o atual e o que se elegeu, mas a gente não sabe qual vai ser a viabilidade delas. Eu digo incerteza de uma forma otimista. Por que eu sou otimista e digo que é uma situação de incerteza.

Pergunta: O que fará para o Brasil de amanhã?

Marília Arraes: O que garantiu a minha eleição em Pernambuco...A bancada do PT sou eu e Carlos Veras3. Tanto a minha eleição quanto a dele, o que garantiu foi nossa presença nas ruas. Eu acho que a gente manter essa presença... De minha parte, além dessa presença nas ruas, nas bases, eu tenho um plano que eu tinha vontade de fazer quando me elegi agora em 2016... Não consegui justamente por que a gente praticamente emendou com a pré-campanha de governo... Mas eu acho que algo muito importante é a gente criar grupos de estudos, grupos de debate para analisar algumas... Analisar, teoria mesmo do que está... da Política, de Filosofia, de diversas questões que ajuda a gente a pensar o momento atual. E se manter na rua, ocupar os espaços que a gente puder ocupar.

Pergunta: Rapidinha: Um livro?

3 Candidato a Deputado Federal eleito em 2018, pelo PT. 
Marília Arraes: Olhe hoje, tem um livro eu tinha lido há uns quinze anos atrás, um livro de Arraes que se chama "O Brasil, o povo e o poder" e eu reli esse ano e fiquei impressionada com a atualidade da obra. Foi um livro escrito na década de 60 e que hoje é muito atual. Quando você observa a questão da subserviência ao capital internacional, que historicamente vem desde que os europeus chegaram no Brasil, até a época que a gente vê hoje, com o golpe que foi dado. Então eu diria que esse livro. Se puder, dê uma lidinha nesse livro que é muito interessante! Quando você lê, parece que você está lendo um livro atual, só que com outros personagens.

Pergunta:Uma música?

Marília Arraes: La Maza de Silvio Rodriguez.

Pergunta: Uma frase?

Marília Arraes: O possível a gente faz, o impossível o povo ajuda a gente a fazer.

\section{Pergunta:Um sonho?}

Marília Arraes: Eu sonho que as pessoas tenham as mesmas oportunidades e a gente tenha uma sociedade justa. Se não fosse esse meu sonho eu estava fazendo outra coisa da vida, sendo egoísta, cuidando só da minha vida.

\section{Referências Bibliográficas}

CARTA CAPITAL. Morre o ex-ministro Fernando Lyra, 2013. Disponível em: https://www.cartacapital.com.br/politica/morre-o-exministro-fernando-lyra Acesso em Dez de 2018.

MOORE, Henrietta. Compreendendo sexo e gênero. (mimeo) Do original em inglês: "Understanding sex and gender", In: Tim Ingold (ed.), 
Companion Encyclopedia of Anthropology. Londres, Routledge, 1997, p. 813-830.

SCOTT, Joan. Gênero, uma categoria útil de análise histórica. SOS Corpo. Recife, SOS Corpo, 1989. (PDF) Original: Joan Scott, Gender: a useful category of historical analyses. Gender and the politics of history. New York, Columbia University Press.1989.

STRATHERN, Marilyn. O gênero da dádiva: problemas com as mulheres e problemas com a sociedade na Melanésia I Mariiyn Strathern; André Villalobos, tradutor. - Campinas, SP: Editora da UNICAMP, 2006. (coleção Gêneros \& Feminismos). 